(C) The Author(s), 2021. Published by Cambridge University Press on behalf of The Nutrition Society. This is an Open Access article, distributed under the terms of the Creative Commons Attribution licence (http://creativecommons.org/licenses/by/4.0/), which permits unrestricted re-use, distribution, and reproduction in any medium, provided the original work is properly cited.

\title{
Carbohydrates deteriorate fatty liver by activating the inflammatory response
}

\author{
Yuqi Gao, Rui Hua, Kaiqiang Hu and Zhao Wang* (1) \\ MOE Key Laboratory of Protein Sciences, School of Pharmaceutical Sciences, Tsinghua University, Beijing, \\ People's Republic of China
}

\begin{abstract}
Non-alcoholic fatty liver disease (NAFLD) was defined in 1980 and has the same histological characteristics as alcoholic liver disease except for alcohol consumption. After 40 years, the understanding of this disease is still imperfect. Without specific drugs available for treatment, the number of patients with NAFLD is increasing rapidly, and NAFLD currently affects more than one-quarter of the global population. NAFLD is mostly caused by a sedentary lifestyle and excessive energy intake of fat and sugar. To ameliorate or avoid NAFLD, people commonly replace high-fat foods with high-carbohydrate foods (especially starchy carbohydrates) as a way to reduce caloric intake and reach satiety. However, there are few studies that concentrate on the effect of carbohydrate intake on liver metabolism in patients with NAFLD, much fewer than the studies on fat intake. Besides, most of these studies are not systematic, which has made identification of the mechanism difficult. In this review, we collected and analysed data from studies on human and animal models and, surprisingly, found that carbohydrates and liver steatosis could be linked by inflammation. This review not only describes the effects of carbohydrates on NAFLD and body lipid metabolism but also analyses and predicts possible molecular pathways of carbohydrates in liver lipid synthesis that involve inflammation. Furthermore, the limitations of recent research and possible targets for regulating inflammation and lipogenesis are discussed. This review describes the effects of starchy carbohydrates, a nutrient signal, on NAFLD from the perspective of inflammation.
\end{abstract}

\section{Key words: Carbohydrates: Inflammation: Fatty liver: mTORC1}

(Received 13 August 2020; revised 14 June 2021; accepted 24 June 2021; accepted manuscript published online 28 June 2021)

\section{Introduction}

\section{- History of carbohydrates}

Carbohydrate consumption has a long history and can be divided into three stages: (1) From the hunting era to the agricultural era, the consumption of meat and plant fruits obtained from primitive hunting and gathering gradually transitioned to the consumption of self-cultivated rice, making rice a staple food. (2) The extensive cultivation of sugar cane made sugar an easily accessible consumer product. Cakes, jams and processed foods began to appear. The production of sugar promoted the transition from original products to refined foods and further consumption of carbohydrates. (3) After the Second World War, ultra-processed carbohydrates, such as glucose syrup, were produced, and the prices of fructose syrup and raw material carbohydrates dropped significantly $^{(1)}$. Since then, carbohydrates have become a ubiquitous and indispensable part of people's lives.

\section{- Classification of carbohydrates and their different characteristics}

Carbohydrates are made of three elements - carbon, hydrogen and oxygen. Carbohydrates are digested and broken down into simpler forms, such as monosaccharides (e.g. glucose and fructose), disaccharides (e.g. lactose) and cellulose after intake (Fig. 1). Although these simpler forms of carbohydrates are composed of similar elements, their functions and metabolic processes in the body are quite different. Monosaccharides and disaccharides include sucrose, glucose, fructose, etc. Polysaccharides mainly include starch and cellulose. Starchy carbohydrates can be divided into amylose, amylopectin and resistant starch according to their structure. Among starchy carbohydrates, amylopectin has the strongest effect on postprandial blood glucose, followed by amylose and resistant starch. Most of the refined starchy carbohydrates that are often encountered in daily life, such as in rice, white noodles and steamed buns, are amylopectin, which is the 'culprit' that causes a sharp increase in blood glucose after meals. Compared with a refined-grain diet, a whole-grain diet does not significantly change insulin sensitivity or the gut microbiome composition but can reduce body weight and systemic low-grade inflammation ${ }^{(2)}$.

\section{Current knowledge}

\section{- 'Carbotoxicity'}

In 2018, the concept of 'carbotoxicity' was proposed, suggesting that non-cellulose digestible carbohydrates are toxic to

* Corresponding author: Dr. Zhao Wang, email: zwang@tsinghua.edu.cn 


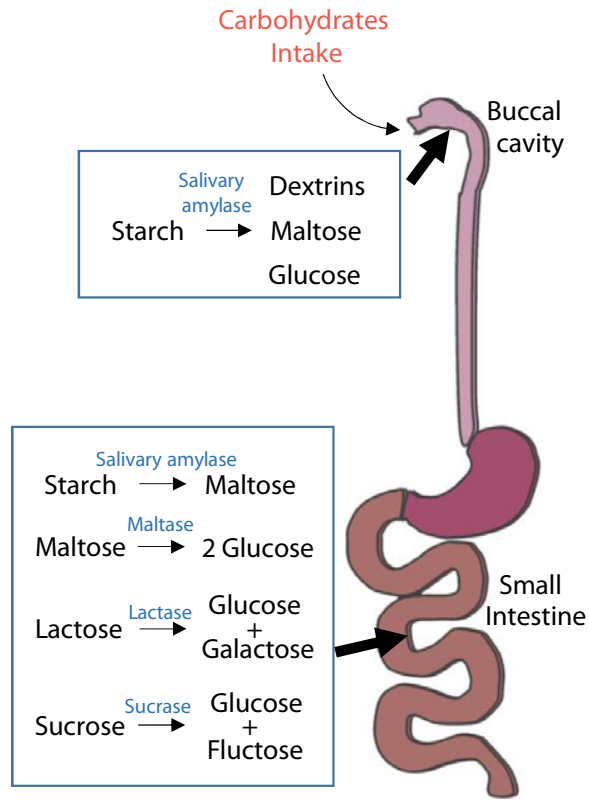

Fig. 1. Digestion of carbohydrates. Starchy carbohydrates are first digested to dextrin, maltose and glucose by salivary amylase, which breaks polysaccharides into short chains. The stomach is not involved in the digestion of carbohydrates; the digestion of carbohydrates mostly takes place in the small intestine. In the small intestine, carbohydrates are completely degraded into simple sugars and enter the bloodstream for the next metabolic process.

some extent ${ }^{(1)}$. A 25-year continuous observation report of 40181 deaths showed that the relationship between carbohydrate intake and all-cause mortality was U-shaped. Carbohydrate intake of $45-55 \% \mathrm{kcal} / \mathrm{d}$ leads to the lowest all-cause mortality; when the daily carbohydrate intake is less than $40 \% \mathrm{kcal}$ or higher than $70 \% \mathrm{kcal}$, all-cause mortality increases significantly ${ }^{(3)}$, which indicates that carbohydrates are not as harmless as we thought previously.

\section{- High carbohydrate intake leads to increased hepatic lipid deposition}

A large number of studies have shown that free sugars (that is, monosaccharides and disaccharides) can promote de novo lipogenesis (DNL) in the liver, resulting in the accumulation of a large number of lipids and leading to NAFLD ${ }^{(4,5)}$. Moreover, studies have shown that hepatic DNL is increased after a highcarbohydrate meal in ob/ob mice, Western-diet-fed mice, and healthy people, indicating the potential harm of carbohydrates to hepatic steatosis ${ }^{(4)}$. Starchy carbohydrates are polysaccharides that require more steps for digestion and decomposition than free sugars. However, because starchy carbohydrates do not have a strong taste stimulus like free sugar, they are often inadvertently ingested in excess, and as the main component of daily staple foods, the intake of starchy carbohydrates is a long-lasting behaviour. Therefore, we speculate that long-term intake of high starchy carbohydrates will have a similar effect as that of free sugars ${ }^{(6,7)}$.

\section{Carbohydrates likely directly cause inflammation}

In existing studies, there is no direct evidence that starchy carbohydrates can cause inflammation, but through integration and analysis of original data from previous studies, there are indications that carbohydrates can lead to inflammation.

A study found that removing stearoyl-CoA desaturase, the rate-limiting enzyme of fatty acid synthesis in the mouse liver, increased endoplasmic reticulum stress and inflammation in mice under a high-carbohydrate diet. After supplementation with the corresponding lipid metabolites, inflammation was significantly improved ${ }^{(8)}$, indicating that carbohydrate intake under impaired lipid metabolism conditions will do the same harm to the body, and all these effects were accompanied by corresponding changes in inflammation levels.

In consideration of the above-mentioned results, we wanted to know whether long-term intake of high starchy carbohydrates leads to chronic inflammation in the body. How does low-level inflammatory damage affect NAFLD? Could a diet high in starchy carbohydrates be an option for improving NAFLD? How do carbohydrates affect NAFLD? In this review, we will answer these questions.

To further demonstrate the relationship among carbohydrates, inflammation, and NAFLD, keywords 'inflammation, carbohydrate', 'carbohydrate, NAFLD', and 'diet, NAFLD, inflammation' were used to search in the PubMed, Clinicalkey, Web of Science and Scopus databases. We retrieved and collected clinical studies that met the requirements described below.

1. Clinical population data;

2. Detailed records of dietary energy intake and carbohydrate intake (\% kcal/d);

3. Measurement of related inflammatory indicators, such as alanine aminotransferase (ALT), aspartate aminotransferase (AST), interleukin-1 $\beta$ (IL-1 $\beta$ ), tumour necrosis factor $\alpha$ (TNF $\alpha$ ), etc.

4. Assessment of body-fat-related parameters, such as body fat index (BMI), total triacylglycerol (TG), total cholesterol (TC), etc. (studies following either requirement 3 or 4 met the selection criteria);

5. Articles published from 2016 to the present;

6. Dietary structure regulation as the main intervention method was preferred.

The data from the selected studies were analysed for correlation between carbohydrate intake and inflammation. Specific citation data and citations are presented in Table 1.

According to the collected clinical raw data (Table 1), carbohydrates have an obvious role under conditions of abnormal lipid metabolism. We selected date of patients with NAFLD and healthy people for correlation analysis. To rule out the effects of other metabolic disorders, patients with NAFLD did not have any other diseases. Carbohydrate intake was divided into total carbohydrate intake, free sugar intake and starchy carbohydrate intake.

Regardless of the sex and age of the patients, there was no correlation between total carbohydrate intake and inflammation level (according to the ALT and AST expression levels) in patients with NAFLD (Fig. 2A, 2D). However, when the effects of starchy carbohydrates and free sugar on liver inflammation were analysed separately, the correlation of AST level with these two types of carbohydrates, which have different metabolic 


\section{NS Nutrition Research Reviews}

Table 1. Information statistics of diet structure and inflammation-related indexes

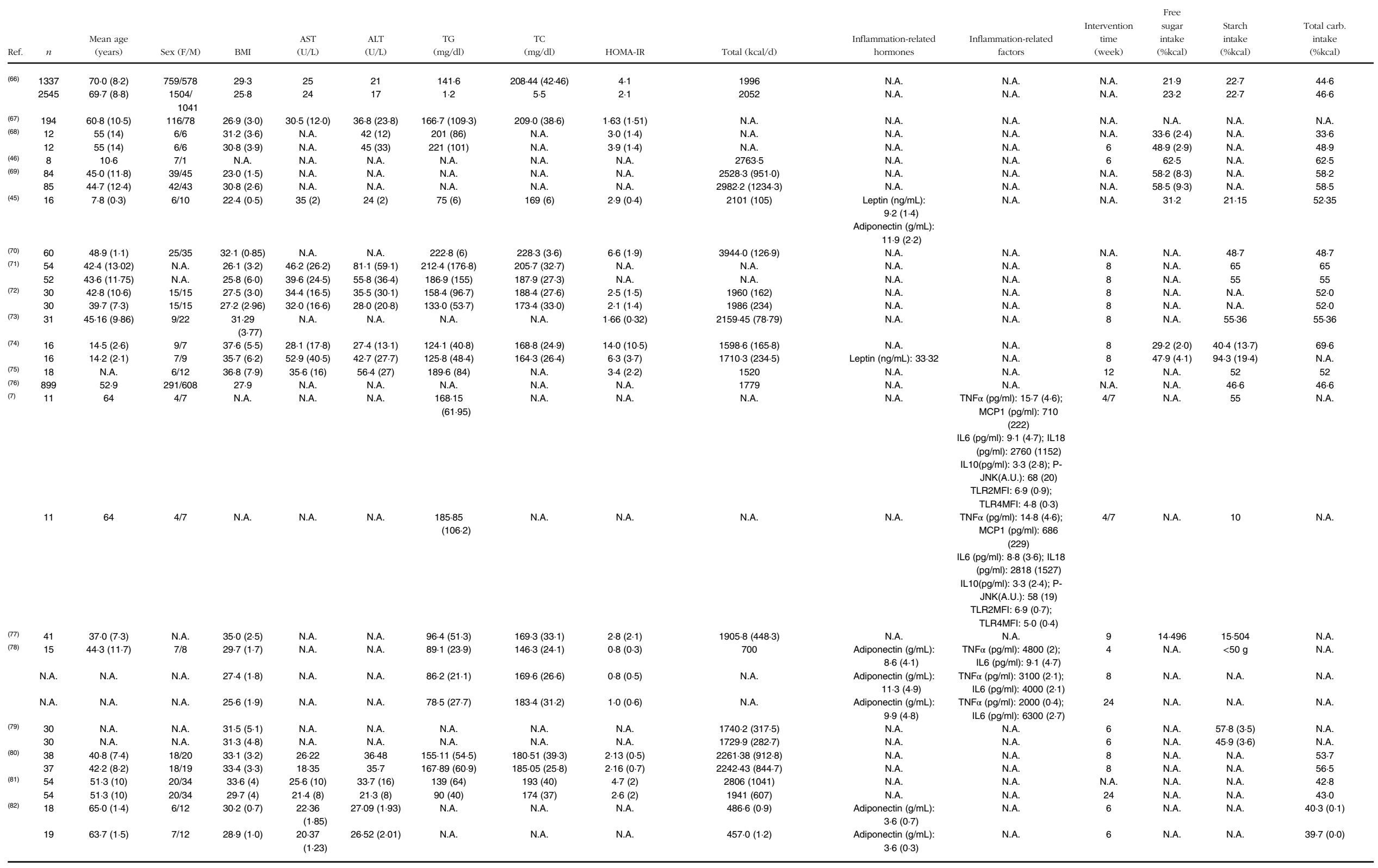


NS Nutrition Research Reviews

Table 1. (Continued)

\begin{tabular}{|c|c|c|c|c|c|c|c|c|c|c|c|c|c|c|c|c|}
\hline Ref. & $n$ & $\begin{array}{c}\text { Mean age } \\
\text { (years) }\end{array}$ & $\operatorname{Sex}(\mathrm{F} / \mathrm{M})$ & BMI & $\begin{array}{c}\mathrm{AST} \\
(\mathrm{U} / \mathrm{L})\end{array}$ & $\begin{array}{c}\text { ALT } \\
(\mathrm{U} / \mathrm{L})\end{array}$ & $\begin{array}{c}\mathrm{TG} \\
\text { (mg/dl) }\end{array}$ & $\underset{\text { (mg/dl) }}{\mathrm{TC}}$ & HOMA-IR & Total (kcal/d) & $\begin{array}{l}\text { Inflammation-related } \\
\text { hormones }\end{array}$ & $\begin{array}{l}\text { Inflammation-related } \\
\text { factors }\end{array}$ & $\begin{array}{l}\text { Intervention } \\
\text { time } \\
\text { (week) }\end{array}$ & $\begin{array}{l}\text { Free } \\
\text { sugar } \\
\text { intake } \\
\text { (\%kcal) }\end{array}$ & $\begin{array}{l}\text { Starch } \\
\text { intake } \\
\text { (\%kcal) }\end{array}$ & $\begin{array}{l}\text { Total carb. } \\
\text { intake } \\
\text { (\%kcal) }\end{array}$ \\
\hline \multirow[t]{2}{*}{ (83) } & 20 & $45.5(8.2)$ & $6 / 14$ & $28.6(4.9)$ & $30.0(7.0)$ & $52.0(13.5)$ & N.A. & N.A. & $2.83(1.07)$ & N.A. & N.A. & N.A. & $24-48$ & N.A. & N.A. & N.A. \\
\hline & 19 & $44.0(9.0)$ & $10 / 9$ & $31.9(4.1)$ & $52.0(23.7)$ & $81.0(57.0)$ & N.A. & N.A. & $5.62(5.71)$ & N.A. & N.A. & N.A. & $24-48$ & N.A. & N.A. & N.A. \\
\hline \multirow[t]{2}{*}{ (84) } & 102 & $11.4(1.45)$ & $43 / 57$ & N.A. & $55(16 \cdot 5)$ & $65(37 \cdot 0)$ & $103(34 \cdot 0)$ & $166(23 \cdot 0)$ & $2.99(2.1)$ & N.A. & N.A. & 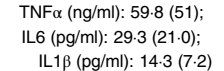 & N.A. & 14.08 & N.A. & $46 \cdot 8$ \\
\hline & 169 & $11 \cdot 6(1.6)$ & $33 / 67$ & N.A. & $42(12.5)$ & $58(21.5)$ & $90(19.0)$ & $156(22 \cdot 5)$ & $2.7(1.67)$ & N.A. & N.A. & 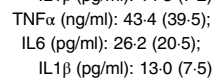 & N.A. & 10.52 & N.A. & $45 \cdot 4$ \\
\hline \multirow[t]{4}{*}{ (85) } & 76 & $49 \cdot 3(10 \cdot 3)$ & $12 / 64$ & $31 \cdot 1(3.9)$ & N.A. & $25 \cdot 3(13 \cdot 5)$ & $71 \cdot 8(41 \cdot 4)$ & N.A. & $4.4(2.6)$ & N.A. & $\begin{array}{c}\text { Adiponectin }(\mathrm{mg} / \mathrm{dl}): \\
9.9(9.4) \\
\text { Leptin }(\mathrm{mg} / \mathrm{dll}): \\
\text { Female } 41.1(23.0) \\
\text { Male } 11.1(7.6)\end{array}$ & N.A. & 72 & N.A. & N.A. & $\begin{array}{l}\text { No more than } \\
300 \mathrm{mg} / \mathrm{d} \text { of } \\
\text { cholesterol }\end{array}$ \\
\hline & 63 & $47.2(9.0)$ & $5 / 58$ & $30.4(3.5)$ & N.A. & $29.0(24.7)$ & $78.7(44.4)$ & N.A. & $4.7(3.4)$ & N.A. & $\begin{array}{c}\text { Adiponectin }(\mathrm{mg} / \mathrm{dll}): \\
10.0(9.0) \\
\text { Leptin }(\mathrm{mg} / \mathrm{dll}): \\
\text { Female } 22.3(6.1) \\
\text { Male } 11.8(6.2)\end{array}$ & N.A. & N.A. & N.A. & N.A. & $\begin{array}{l}\text { No more than } \\
300 \mathrm{mg} / \mathrm{d} \text { of } \\
\text { cholesterol }\end{array}$ \\
\hline & 73 & $47.0(8.9)$ & $11 / 62$ & $31.0(4.5)$ & N.A. & $25.8(12.4)$ & $73.5(41.9)$ & N.A. & $4.7(3.8)$ & N.A. & $\begin{array}{c}\text { Adiponectin }(\mathrm{mg} / \mathrm{dll}): \\
9.6(8.3) \\
\text { Leptin }(\mathrm{mg} / \mathrm{dll}): \\
\text { Female } 33.7(25.8) ; \\
\text { Male } 11.3(9.0)\end{array}$ & N.A. & N.A. & N.A. & N.A. & Less than $40 \mathrm{~g} / \mathrm{d}$ \\
\hline & 66 & $47.9(9.8)$ & $3 / 63$ & $31.0(3.3)$ & N.A. & $28.8(12.4)$ & $66.5(41.9)$ & N.A. & $4.5(3.8)$ & N.A. & $\begin{array}{c}\text { Adiponectin }(\mathrm{mg} / \mathrm{dll}): \\
13.2(9 \cdot 4) \\
\text { Leptin }(\mathrm{mg} / \mathrm{dl}): \\
\text { Female } 30.8(1.3) ; \\
\text { Male } 13.6(7.9)\end{array}$ & N.A. & N.A. & N.A. & N.A. & Less than $40 \mathrm{~g} / \mathrm{d}$ \\
\hline (86) & 169 & $38 \cdot 3(6 \cdot 9)$ & 60/109 & $27.9(2.7)$ & $36.0(19.4)$ & $39.0(21.5)$ & $172.9(77.9)$ & $189.8(31.2)$ & $0.6(0.8)$ & $1996.6(1.58)$ & N.A. & N.A. & N.A. & N.A. & N.A. & 8.63 \\
\hline \multirow{4}{*}{ (87) } & 173 & $37.2(7.0)$ & $43 / 130$ & $27.4(3.19)$ & $33.1(11.4)$ & $34 \cdot 4$ (13.3) & $146.5(66.0)$ & $177.7(30.0)$ & $0.4(0.6)$ & $1806.6(1.28)$ & N.A. & N.A. & N.A. & N.A. & N.A. & 8.81 \\
\hline & 36 & $44.0(10.8)$ & $13 / 23$ & $31.3(0.58)$ & $31 \cdot 3(1 \cdot 6)$ & $46.5(3.01)$ & $199.4(14.9)$ & $189.7(5.5)$ & $3.6(0.22)$ & 2157.5 (437.1) & N.A. & N.A. & N.A. & N.A. & N.A. & 55.32 \\
\hline & 37 & $39.8(11.0)$ & 15/22 & $30.3(0.64)$ & $30.4(1.3)$ & $45.9(2.4)$ & $197 \cdot 6(13)$ & $185.0(5.3)$ & $4.3(0.25)$ & $2160 \cdot 2(385 \cdot 2)$ & N.A. & N.A. & N.A. & N.A. & N.A. & 54.94 \\
\hline & 37 & $38.3(10 \cdot 1)$ & $14 / 23$ & $30.5(0.93)$ & $32 \cdot 5(1 \cdot 2)$ & $50 \cdot 2(2 \cdot 6)$ & $211.8(10 \cdot 4)$ & $198 \cdot 3(6 \cdot 1)$ & $3.9(0.21)$ & $2162 \cdot 3(426 \cdot 4)$ & N.A. & N.A. & N.A. & N.A. & N.A. & 54.73 \\
\hline \multirow[t]{4}{*}{ (88) } & 62 & 41.0 (12.4) & N.A. & $21.7(2.0)$ & $20.5(15.6)$ & $24 \cdot 5(24 \cdot 2)$ & $85 \cdot 3(77 \cdot 5)$ & N.A. & $23.7(36.2)$ & $\begin{array}{l}1859.0(575.1) \\
\text { (5) }\end{array}$ & N.A. & N.A. & $\begin{array}{l}\text { N.A. } \\
\text { N.A. }\end{array}$ & N.A. & N.A. & $55 \cdot 9(8.4)$ \\
\hline & 23 & $43.8(11.9)$ & N.A. & $23.5(1.4)$ & $37.0(17.6)$ & $67.8(43.5)$ & $146.7(67.0)$ & N.A. & $38.0(34.3)$ & $1963.6(417.6)$ & N.A. & N.A. & N.A. & N.A. & N.A. & $60.0(6.6)$ \\
\hline & 59 & $40.8(8.2)$ & N.A. & $28.3(2.8)$ & $24.8(15 \cdot 1)$ & $30.1(27.6)$ & $157.4(107.5)$ & N.A. & $32.6(44.4)$ & $1931.0(502.0)$ & N.A. & N.A. & N.A. & N.A. & N.A. & $58.4(6.7)$ \\
\hline & 65 & $38.9(11 \cdot 1)$ & N.A. & $29.7(3.9)$ & $54.0(31.9)$ & $87.4(50.4)$ & $196.9(137.5)$ & N.A. & $\begin{array}{l}89.7 \\
(124.7)\end{array}$ & $2051 \cdot 6(541 \cdot 1)$ & N.A. & N.A. & N.A. & N.A. & N.A. & $58.0(7.3)$ \\
\hline \multirow[t]{2}{*}{ (89) } & 671 & $53 \cdot 6(16 \cdot 9)$ & $481 / 190$ & $21.9(2.9)$ & $21 \cdot 2(7.0)$ & $18.1(10.8)$ & $81 \cdot 2(43 \cdot 6)$ & $202.8(36 \cdot 3)$ & N.A. & $1782.4(564.7)$ & $\begin{array}{c}\text { Adiponectin }(\mu \mathrm{gg} / \mathrm{mL}): \\
12.1(6.3) \\
\text { Leptin }(\mathrm{ng} / \mathrm{mL}): 8.8 \\
(5.5)\end{array}$ & IL6 (pg/ml): 2.00 (7.27); & N.A. & N.A. & N.A. & 54.9 \\
\hline & 200 & $55 \cdot 3(13 \cdot 3)$ & $117 / 83$ & $25.8(3.6)$ & $26 \cdot 3(11 \cdot 7)$ & $32 \cdot 3(20.3)$ & $131.0(87.5)$ & $211.8(33.7)$ & N.A. & $1849 \cdot 3(530 \cdot 6)$ & $\begin{array}{c}\text { Adiponectin }(\mu \mathrm{g} / \mathrm{mL}): \\
7.2(2 \cdot 8) \\
\text { Leptin (ng/mL): } 12 \cdot 8 \\
(8 \cdot 4)\end{array}$ & IL6 (pg/ml): 1.64 (1.80); & N.A. & N.A. & N.A. & 55.6 \\
\hline \multirow[t]{2}{*}{ (90) } & 16 & $47 \cdot 9(1 \cdot 1)$ & 0/16 & $27.7(0.4)$ & N.A. & $12(2)$ & N.A. & $4.7(0.2)$ & $2.2(0.3)$ & N.A. & $\begin{array}{c}\text { Adiponectin }(\mu \mathrm{g} / \mathrm{mL}): \\
8.8(1.0)\end{array}$ & $\begin{array}{c}\text { FGF21 }(\mathrm{pg} / \mathrm{mll}): 197 \cdot 3 \\
(24 \cdot 3)\end{array}$ & 4 & 20 & N.A. & 65 \\
\hline & 16 & $47 \cdot 9(1 \cdot 1)$ & 0/16 & $27.7(0.4)$ & N.A. & $9(1)$ & N.A. & $4.4(0.2)$ & $2.2(0.2)$ & N.A. & $\begin{array}{c}\text { Adiponectin }(\mathrm{\mu g} / \mathrm{mL}) \text { : } \\
7.2(0.9)\end{array}$ & $\begin{array}{c}\text { FGF21 }(\mathrm{pg} / \mathrm{mll}): 248 \cdot 1 \\
(37.7)\end{array}$ & 4 & N.A. & N.A. & 40 \\
\hline \multirow{3}{*}{$\begin{array}{l}(92) \\
(92)\end{array}$} & 10 & $58.2(2.8)$ & $5 / 5$ & $30.6(2.0)$ & $37(5)$ & $38(7)$ & N.A. & N.A. & N.A. & 1444 & N.A. & N.A. & 0.85 & N.A. & N.A. & 6.37 \\
\hline & 25 & $50 \cdot 6(2 \cdot 1)$ & $25 / 0$ & $32 \cdot 6(1 \cdot 2)$ & N.A. & $33.8(3.6)$ & N.A. & N.A. & N.A. & 1982.1 (92.3) & N.A. & N.A. & N.A. & 9.4 & N.A. & $43 \cdot 3$ \\
\hline & 17 & $48 \cdot 8(2 \cdot 3)$ & $0 / 17$ & $32 \cdot 3(1 \cdot 2)$ & N.A. & $41 \cdot 8(5 \cdot 3)$ & N.A. & N.A. & N.A. & $2509.5(135.3)$ & N.A. & N.A. & N.A. & 7.5 & N.A. & 41.8 \\
\hline
\end{tabular}




\section{NS Nutrition Research Reviews}

Table 1. (Continued)

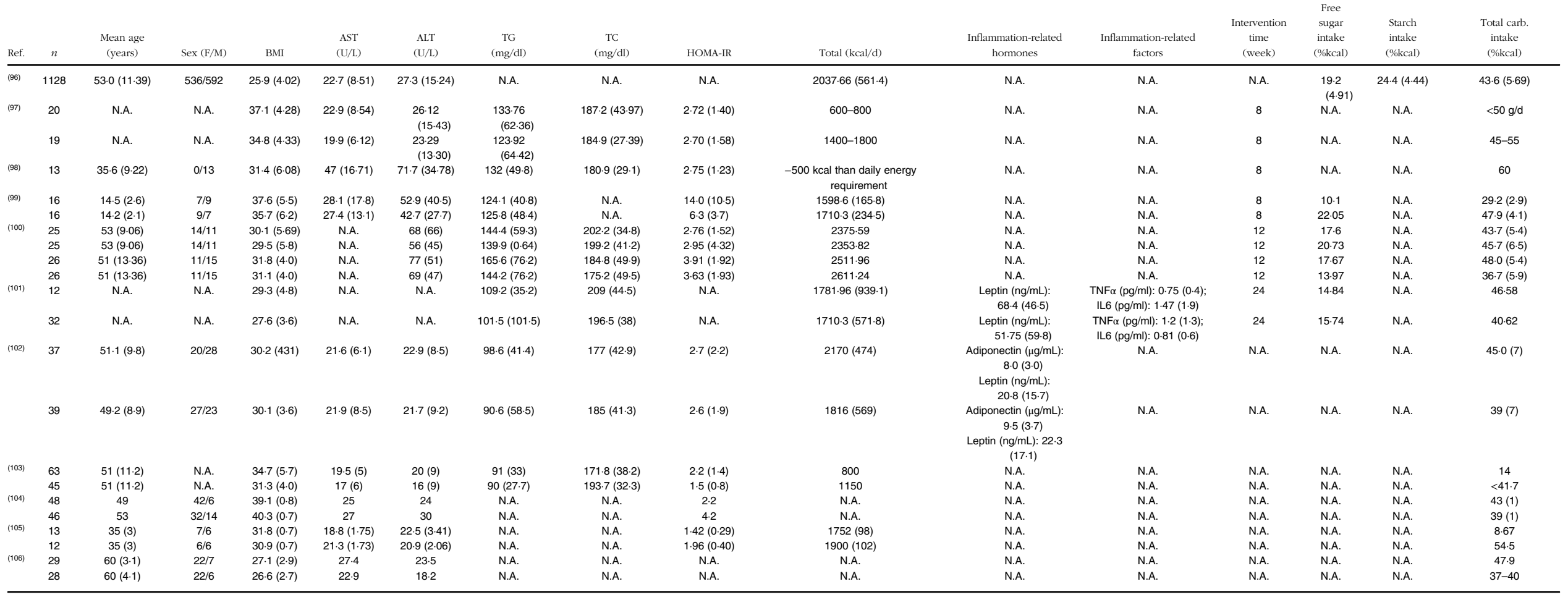

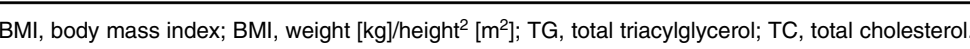


(A)

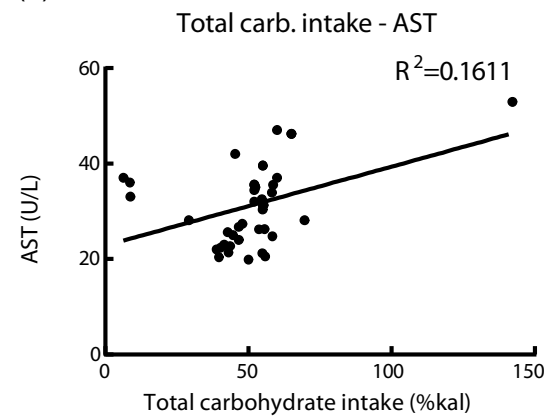

(D)

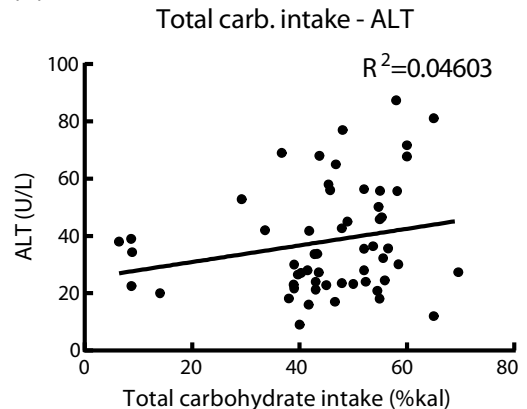

(B)

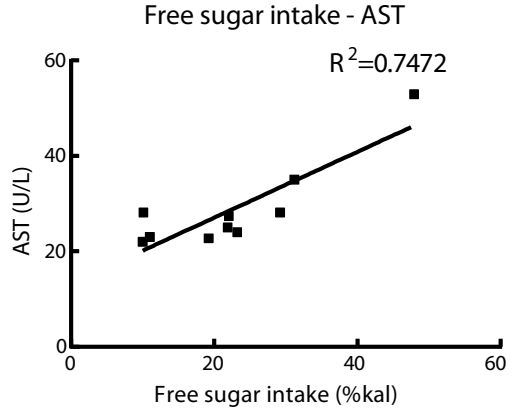

(E)

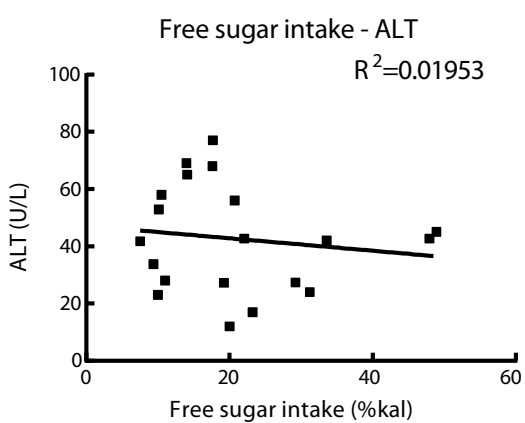

(C)

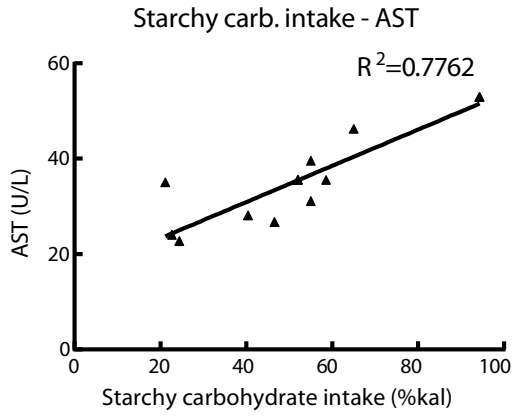

(F)

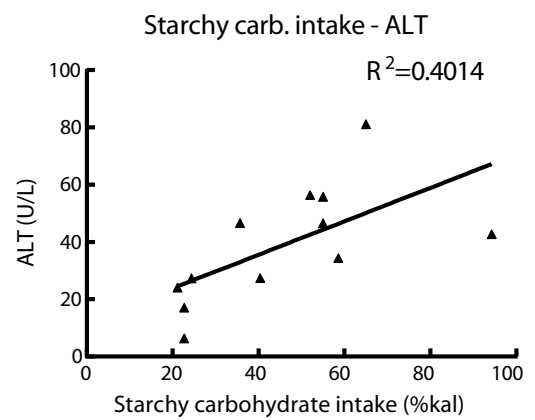

Fig. 2. Correlation analysis of carbohydrates and ALT and AST. Transaminase levels reflect inflammation level in the liver. The AST and ALT data were collected from previous studies, and the correlations with total carbohydrate intake $(A, D)$, free sugar intake $(B, E)$ and starchy carbohydrate intake $(C, F)$ were analysed separately.

characteristics, improved significantly and presented the same trend. The correlation (slope level) of starchy carbohydrates with AST (Fig.2C) and ALT (Fig. 2F) showed a positive trend which is the same as that of total carbohydrates. Moreover, the correlation of starchy carbohydrates with ALT (Fig. 2B) was much stronger than that of free sugar with ALT (Fig. 2E), which indicates that the relationship between starchy carbohydrates and inflammation seems to be closer than that between inflammation and free sugar.

In addition, we analysed the correlation between carbohydrate intake and blood lipid levels (Fig. 3). Regardless of age and sex differences, we found that there was no correlation between total carbohydrate intake or starchy carbohydrate intake and blood lipids, but there was a correlation between free sugar and TG, which indicates that the intake of starchy carbohydrates did not affect the lipid content directly in the body.

We hypothesise that there is an association between the lipid content affected by starchy carbohydrates and inflammation. In previous studies, inflammation and lipid deposition were considered to be associated, though the causal relationship was not discussed in depth. Therefore, we analysed the collected blood lipid and inflammation data (Fig. 4). The results indicated that TG was correlated with AST and ALT (Fig. 4A, 4B), further supporting our hypothesis. These findings show that inflammation and lipid production are not independent processes.

\section{Factors leading to liver inflammation}

NAFLD is a representative disease of abnormal lipid metabolism in the body and is usually accompanied by increased inflammation and lipid deposition. It is believed that an increase in the level of inflammation promotes the progression of NAFLD to non-alcoholic steatohepatitis (NASH). Since there is no mechanistic evidence that carbohydrates cause inflammation in NAFLD, we searched the relevant literature in PubMed, summarised the main pathways and factors that cause inflammation in NAFLD (Table 2) and compared them with carbohydrateinduced metabolic changes to identify possible pathways by which carbohydrates cause inflammation.

According to recent reports, the main pathways and factors leading to inflammation in NAFLD are as follows:

\section{PARP-1/PPAR $\alpha / S I R T 1$ pathway}

Peroxisome proliferator-activated receptor $\alpha$ (PPAR $\alpha)$ is a sensor of fatty acid synthesis and is considered to be a key factor in fatty liver and lipid steatosis ${ }^{(9,10)}$. Recently, a large number of studies have shown that PPAR $\alpha$ plays an important role in balancing glucose homeostasis ${ }^{(11)}$. Moreover, PPAR $\alpha$ can regulate lipid metabolism and affect the levels of downstream inflammatory factors $^{(12-15)}$. The PPAR $\alpha$ pathway regulates inflammation mainly through the PPAR $\alpha-S I R T 1$ pathway. Sirt1 can inhibit the up-regulation of fatty acid oxidation caused by fatty acids, while the reduction in fatty acid oxidation leads to an increase in fatty acids, the raw material of lipids, thereby causing lipid accumulation and inflammation $^{(16)}$. At present, PARP-1 has been reported to affect PPAR $\alpha$ through poly(ADP-ribosyl)ation, which has been shown to inhibit the activity of the PPAR $\alpha$ signalling pathway by inhibiting the binding of PPAR $\alpha$ to SIRT1 ${ }^{(17)}$ (Fig. 5A and 5D). In addition, PARP-1 can further lead to hepatic steatosis and metabolic disorders via the PI3K/AKT pathway. Puerarin can effectively ameliorate NAFLD by inhibiting this process $^{(18)}$. 
(A)

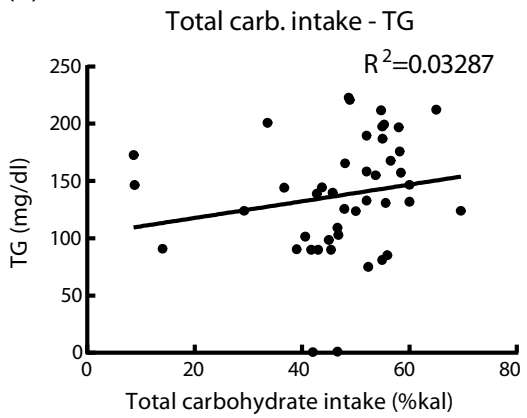

(D)

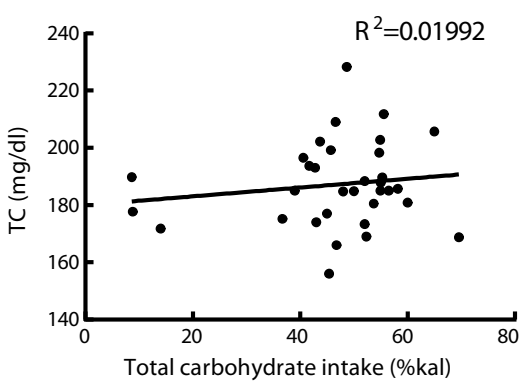

(B)

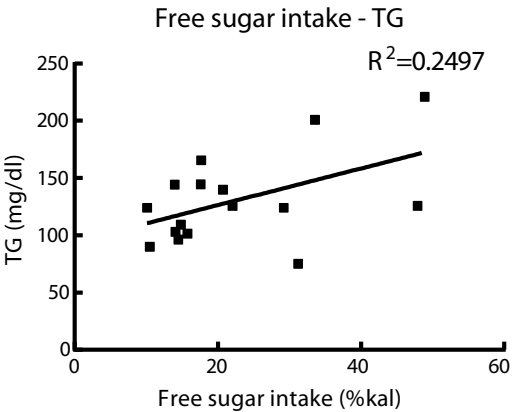

(E)

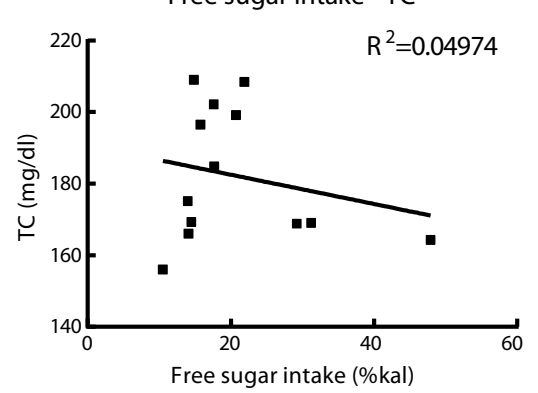

(C)
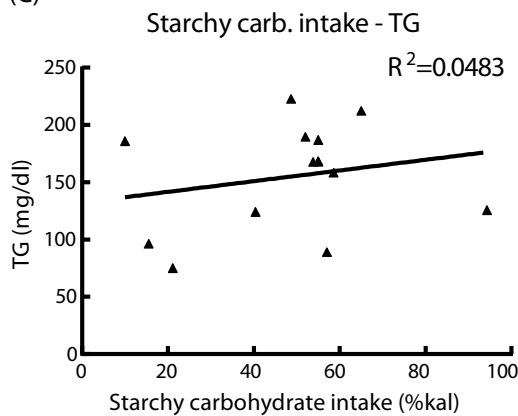

(F)

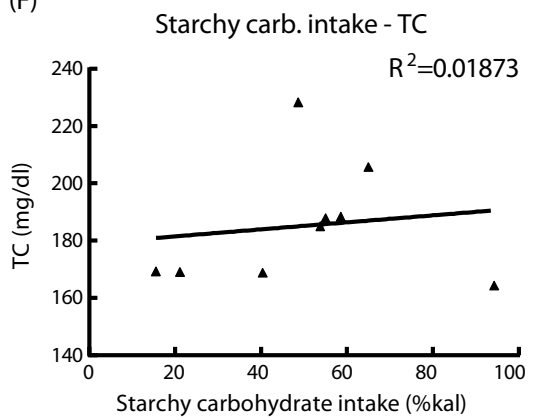

Fig. 3. Correlation analysis of carbohydrates and blood lipid levels. Total triacylglycerol and total cholesterol data were collected from previous clinical studies, and the correlations with total carbohydrate intake $(A, D)$, free sugar intake $(B, E)$ and starchy carbohydrate intake $(C, F)$ were analysed separately. TG, total triacylglycerol; TC, total cholesterol.

(A)

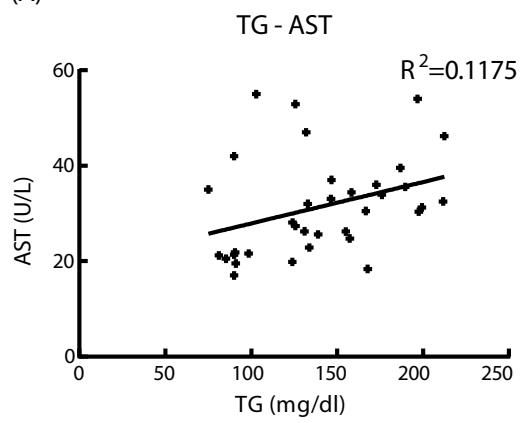

(C)

TC - AST

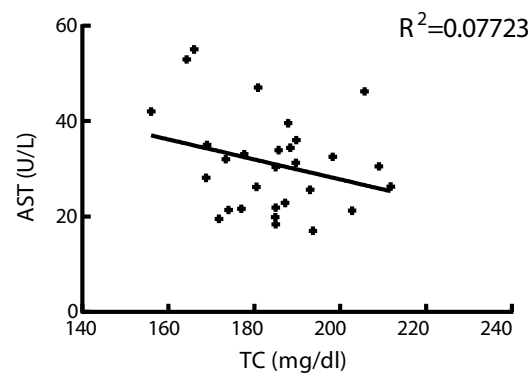

(B)

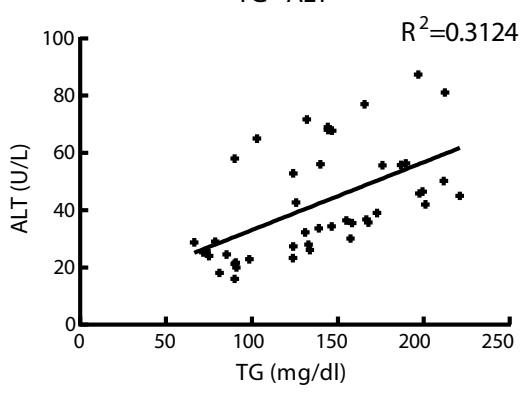

(D)

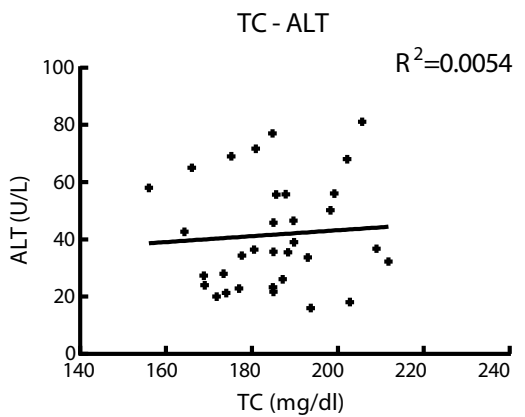

Fig. 4. Correlation analysis of blood lipid levels and transaminase content. Data were collected from previous clinical studies, and the correlations with total carbohydrate intake $(A, D)$, free sugar intake $(B, E)$ and starchy carbohydrate intake $(C, F)$ were analysed separately. TG, total triacylglycerol; TC, total cholesterol.

\section{$N F-\kappa B$}

$\mathrm{NF}-\kappa \mathrm{B}$ is a very important nuclear transcription factor that is involved in the inflammatory response, immune response, stress response and other processes related to immune inflammation.
NF- $\mathrm{kB}$ in cells is usually found in p65/p50 subunits in dimeric form. Under resting conditions, the NF- $\mathrm{KB}$ dimer combines with

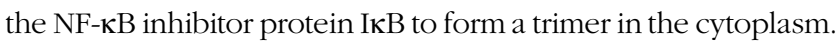
When cells are stimulated, I $\kappa \mathrm{B}$ is phosphorylated and separated 
Table 2. Main pathways and regulatory factors that regulate hepatic inflammation

\begin{tabular}{|c|c|c|c|c|}
\hline Pathways & Specific action pathway & Regulatory factors & $\begin{array}{l}\text { Effect on } \\
\text { inflammation }\end{array}$ & Ref. \\
\hline $\operatorname{PPAR} \alpha$ & $\begin{array}{l}\text { PPAR } \alpha-S I R T 1 \\
\text { PARP-1-PI3K-AKT }\end{array}$ & $\begin{array}{l}\text { PARP-1; } \\
\text { NAD + content; } \\
\text { Hepatic mitochondrial function }\end{array}$ & Inhibit & (17) \\
\hline$N F \kappa B$ & $\begin{array}{l}\text { NFkB-inflammatory factors } \\
\text { (TNF } \alpha, \text { IL-1 } \beta, \text { MCP1) } \\
\text { NFKB-p-JUN }\end{array}$ & $\begin{array}{l}\text { Fructose; Uric acid; } \\
\text { Neutrophile granulocyte; } \\
\text { Gasdermin D; FFA; MPST }\end{array}$ & Promote & (20) \\
\hline Inflammasome & $\begin{array}{l}\text { Caspase } 1 \text { and IL- } 1 \beta \\
\text { Insulin signalling pathway } \\
\text { Oxidative stress }\end{array}$ & $\begin{array}{l}\text { ATP; Uric acid; } \\
\text { Palmitic acid; Cholesterol crystals; } \\
\text { ROS }\end{array}$ & Promote & (107); (23) (25) \\
\hline $\begin{array}{l}\text { Immune cells and macrophages in } \\
\text { liver }\end{array}$ & $\begin{array}{l}\text { Liver B cells-IL-6, TNF } \alpha \\
\text { Macrophages-STING-C-JUN } \\
\text { Kuffer cell-IL-1 } \beta, \text { TNF } \alpha\end{array}$ & $\begin{array}{l}\text { Micro-organism; miRNA } \\
\text { Any factors that can activate immune } \\
\text { system }\end{array}$ & Promote & $\begin{array}{c}\text { (23); } \\
\text { (26); }(27)\end{array}$ \\
\hline MAPK & $\begin{array}{l}\text { CD36-JNK } \\
\text { Liver cytokine-ERK1/2 }\end{array}$ & $\begin{array}{l}\text { Heparin (liver cytokine); Macrophages; } \\
\text { CD36; High-carbohydrate diet }\end{array}$ & Promote & (29) \\
\hline Toll-like receptors 4 pathway & $\begin{array}{l}\text { TLR4-MAPK-JNK-NFKB/AP-1 } \\
\text { TLR4-ERK-IKK }\end{array}$ & $\begin{array}{l}\text { Pro-inflammatory response } \\
\text { Motif-containing } 1 \text { (TMBIM1) } \\
\text { Lysosomal defect-mediated degradation }\end{array}$ & Promote & (32) \\
\hline ROS & $\begin{array}{l}\text { ROS-NF-kB } \\
\text { ROS-Oxidative stress of } \\
\quad \text { mitochondria }\end{array}$ & $\begin{array}{l}\text { Mitochondrial respiratory chain; } \\
\text { Cytochrome P450 system; } \\
\text { Auto-oxidation of haem proteins; } \\
\text { NADPH oxidase complex; xanthine } \\
\text { oxidase }\end{array}$ & Promote & (36); (37) \\
\hline Intestinal flora & $\begin{array}{l}\text { Intestinal flora metabolites } \\
\text { Intestinal flora-bile acids }\end{array}$ & $\begin{array}{l}\text { Diet; } \\
\text { Bile acids; }\end{array}$ & Depends & (42); ${ }_{(21)}^{(43)}$ \\
\hline Organs effect on liver inflammation & $\begin{array}{l}\text { Adipose tissue } \\
\text { Pancreas }\end{array}$ & $\begin{array}{l}\text { Lipolysis; } \\
\text { Macrophages }\end{array}$ & Depends & (47); ${ }^{(46)}$ \\
\hline
\end{tabular}

from the NF- $\kappa \mathrm{B}$ trimer, and the activated NF- $\kappa \mathrm{B}$ then migrates to the nucleus and exerts its activity ${ }^{(19)}$ (Fig. 5B). The downstream factors of NF- $\kappa \mathrm{B}$, including TNF- $\alpha$, IL-1, monocyte chemoattractant protein 1 (MCP1), etc., are considered to be the main causes of liver inflammation and systemic inflammation.

Studies have reported that, in leaner patients with fatty liver, which is partly caused by excessive carbohydrate intake, the uric acid content is positively correlated with liver inflammation. Uric acid stimulates downstream MCP1 through the NF- $\mathrm{BB}$ signalling pathway and promotes liver inflammation ${ }^{(20)}$. A previous study found that the metabolism of fructose by fructose kinase $\mathrm{C}$ increased ATP consumption, nucleotide conversion and uric acid production $^{(21)}$. Therefore, the activation of the NF- $\kappa B$ signalling pathway by uric acid may be one of the mechanisms by which carbohydrates cause liver inflammation (Fig. 5A).

\section{Inflammasomes}

Inflammasomes are multi-protein complexes assembled by pattern recognition receptors in the cytoplasm and are a crucial part of the natural immune system ${ }^{(22)}$. Inflammasomes recruit and activate Caspase-1, a pro-inflammatory protein, by recognising pathogen-related molecules and host signals, thereby promoting the maturation of cytokine precursors and pyroptosis, which induce inflammation (Fig. 5B).

Experiments have shown that the NLRP3 inflammasome can cause increased inflammation and liver fibrosis. By adding MCC950, a small-molecule inhibitor of NLRP3, liver fibrosis is reversed, and the expression of Caspase- 1 and IL- $1 \beta$ in the liver is restored to normal levels ${ }^{(23)}$. In addition, inflammasomes can also be activated by uric acid, triggering lipid accumulation and damage to liver cells through the insulin signalling pathway ${ }^{(24)}$. Plasma uric acid levels are correlated with the glycaemic index of food ${ }^{(25)}$, and starchy carbohydrates and free sugars are substances with a high glycaemic index; therefore, it is possible that starchy carbohydrates and free sugars can activate inflammasomes through uric acid, leading to further increases in oxidative stress and inflammation in the liver.

\section{Immune cells and macrophages in the liver}

Both immune cells and macrophages in the liver have a vital role in mediating the immune response and regulating inflammation levels in the body.

Liver B cells can express high levels of IL- 6 and TNF $\alpha$ and show significant inflammation under lipopolysaccharide stimulation ${ }^{(26)}$. A previous study found that macrophages could mediate transmembrane protein 173 (TMEM173 or STING) signalling pathway and activate the innate immune response regulated by type I interferon. After knocking out STING, the mRNA levels of c-JUN N-terminal phosphorylation kinase, p65, TNF $\alpha$, IL-1 $\beta$ and IL-6 were significantly reduced, therefore improving liver inflammation and fibrosis ${ }^{(27)}$.

Kupffer cells in the liver participate in liver immunity, maintain the stability of the body environment and resist the invasion of foreign pathogens (Fig. 5C). Hepatocyte regeneration is stimulated by sustained release of TNF- $\alpha$ and IL- $1 \beta$. In vivo experiments have shown that cholesterol can stimulate Kupffer cells to secrete IL-1 $\beta$, which may be why patients with fatty liver generally show low-level inflammation ${ }^{(23)}$. Due to the presence of inflammation, additional intervention with high carbohydrates will exacerbate the deterioration of fatty liver and make inflammation spread. 
(A)

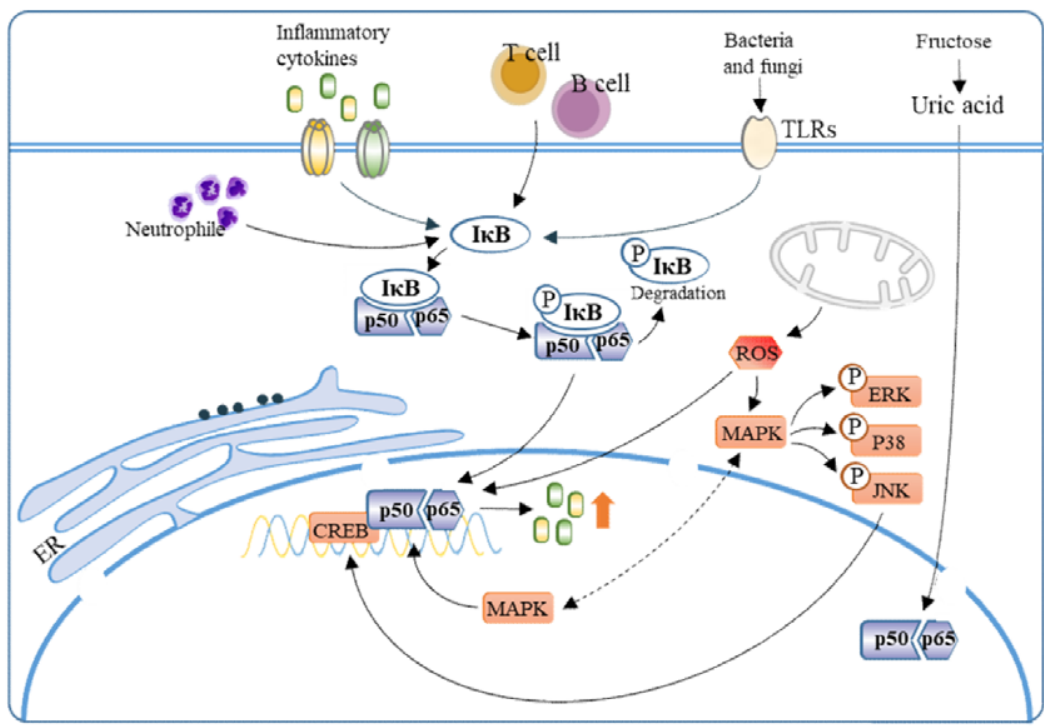

(B)

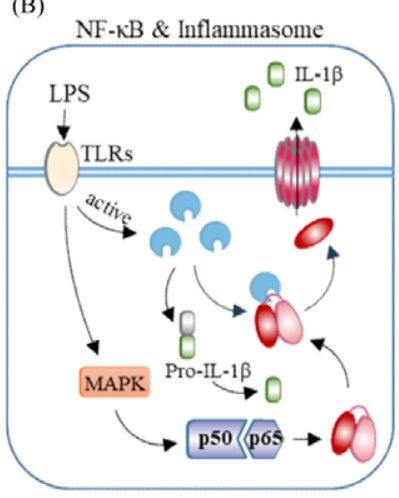

(C)

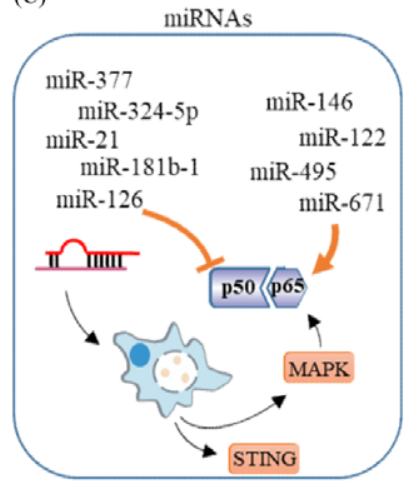

(D)

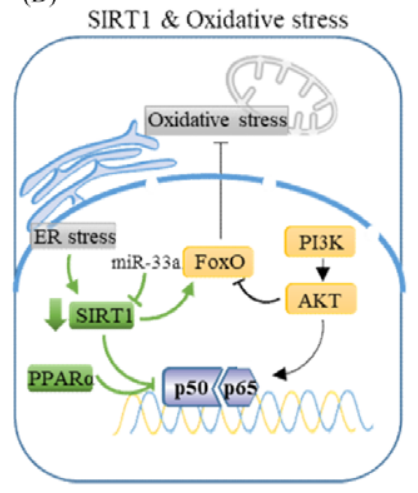

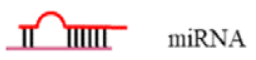

p50 05

Active NF-kB

Gasdermin D (GSDMD)

GSDMD pore $\cap$ Caspase-1

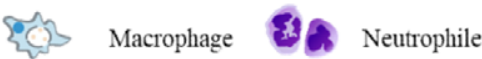

Inflammatory cytokine receptors

OD Inflammatory cytokines

(IL-6, IL-8, IL-1 $\beta$, TNF- $\alpha$, MCP-1)

TLRs

$T$ cell

B cell

Fig. 5. Main pathways and regulatory factors leading to liver inflammation. (A) The NF-kB signalling pathway causes hepatic inflammation by activating inflammatory factor expression and the factors that affect NF-kB. (B) Activation of the NF-kB pathway leads to the release of a large number of inflammatory cytokines. (C) miRNAs regulate intrahepatic inflammation by affecting macrophages and the NF-kB signalling pathway. (D) The effect of oxidative stress and SIRT1 on NF-kB. (E) Effect of intestinal flora changes and abundance as well as intestinal barrier permeability on inflammatory cytokine release.

\section{MAPK pathway}

MAPK signalling pathways mainly include the ERK, JNK and P38 pathways, which are currently recognised as the main inflammation-generating pathways (Fig. 5A-5C).

The liver is a non-lipid storage organ, and the lipid content is the result of the dual action of lipid production and lipid clearance. Studies have found that the lipid transporter CD36 can cause liver inflammation by activating $\mathrm{JNK}^{(28)}$. When palmitoylation of CD36 is inhibited in HepG2 liver cells, the level of the CD36/Fyn/Lyn complex is decreased, resulting in less entry of fatty acids into the cells. In addition, inhibiting the JNK signalling pathway relieves inflammation ${ }^{(29)}$. High carbohydrates were proved to increase the expression of CD36, leading to increased transport of fatty acids into the liver and activation of JNK, which gives a possible explanation as to why lipid deposition and inflammation are always associated.

\section{TLR4 signalling pathway}

Toll-like receptor 4 (TLR4) belongs to a highly conserved family of receptors, the family of model receptors. TLR 4 functions by recognising sub-patterns related to conservative pathogens and therefore represents the first line of defence against them. In addition, TLR4 is linked to endogenous molecules caused by inflammatory damage ${ }^{(30)}$ (Fig. 5A). Therefore, TLR4 is a key receptor triggered by the pro-inflammatory response to exogenous and endogenous ligands mediated by infectious stimuli and plays a key role as an amplifier of the inflammatory response ${ }^{(31)}$. TLR4 leads to the production of inflammatory cytokines by activating MAPK, JUN N-terminal kinase, p38, ERK1/2 and IкB kinase complex (IKK). The classic liver inflammation model induced by lipopolysaccharide occurs through activation of the TLR4 signalling pathway. In addition to the classic NF- $\kappa \mathrm{B}$ pathway, lysosomal defect-mediated protein degradation of TLR4 is another key process of steatohepatitis ${ }^{(32)}$.

\section{Reactive oxygen species (ROS)}

ROS come from a wide range of sources, including the mitochondrial respiratory chain, the cytochrome P450 system (CYP450), the auto-oxidation of haem proteins, the NADPH oxidase complex, xanthine oxidase and other cellular systems. Inflammatory 
cells such as macrophages, neutrophils and monocytes migrate to infected sites and attack invaders under inflammatory conditions. As a result, pathogenic micro-organisms, intermediaries or infected cells are killed and degraded. Simultaneously, release of a large number of reactive oxygen radicals leads to oxidative stress $^{(33)}$. If healthy tissues are not reconstructed in time, chronic inflammation will make the immune system produce low concentrations of molecules such as prostaglandins and NF- $\kappa \mathrm{B}$ continuously. Excessive ROS maintain the activation of NF- $\kappa \mathrm{B}$ for a long time, resulting in the continuous release of inflammatory mediators, thereby causing chronic inflammation $^{(34)}$ (Fig. 5D). The inflammation caused by starchy carbohydrates is a form of chronic inflammation. Moreover, the increase in uric acid levels caused by high carbohydrate intake not only causes insulin resistance but also increases the oxidative stress of mitochondria ${ }^{(25)}$.

Lipid intake is very important for the production of CYP, and CYP is involved in fatty acid metabolism ${ }^{(35)}$. Although lipid intake is low on a high-carbohydrate diet, our research found that a high-carbohydrate diet also increases the expression of CYP, which promotes the generation of oxidative stress and ROS, and leads to inflammation. The same study corroborated our finding that, when CYP450 2E1 is inhibited, fatty liver disease caused by a high-fat diet is alleviated ${ }^{(36)}$. A high-fat, high-sucrose diet increases the expression of Cyp1a2 in only 1 week, and the mRNA expression of Cyp1a1, $2 b 10$ and 2c29 increases significantly after 12 -week diet intervention. Resveratrol, a polyphenolic antioxidant, decreases lipid accumulation after administration to mice with NAFLD but does not change the expression of CYP, indicating that CYP regulates the generation of ROS upstream $^{(36)}$.

Oxidative stress is caused by high levels of ROS, leading to apoptosis and necrosis. ROS can also cause a chain reaction between free radicals and unsaturated fatty acids to form toxic lipid intermediates ${ }^{(37)}$. In addition, carbohydrates likely activate ROS through CYP, which aggravates lipid metabolism disorders due to oxidative stress.

\section{Intestinal flora}

With the development of sterile animals and sequencing technology, intestinal flora has been found to participate in various processes of life. The abundances, types and proportions of intestinal flora constitute different intestinal metabolite microenvironments. Also, the metabolites from the flora digested by the intestinal can be transmitted to various organs through the intestinal barrier. The impact of the diet on the body is no longer considered as a single source of energy or nutrients but likely an effect on the whole body through the intestinal flora ${ }^{(38)}$.

Starchy carbohydrates such as potatoes and rice are rich in resistant starch, which has been shown to affect the abundance and composition of the intestinal flora in the body. Among female cynomolgus monkeys fed a high-carbohydrate high-fat diet, or a Mediterranean diet, the group fed a Mediterranean diet have a richer microbiome diversity, higher Firmicutes-toBacteroides ratio, and higher Clostridiaceae and Lactobacillaceae abundances $^{(39)}$; a similar result was also found in humans ${ }^{(40)}$. Additionally, when the normal intestinal flora of wild-type (WT) mice was transplanted into germ-free mice, body weight and indicators in serum were similar to those of WT mice ${ }^{(41)}$. Mother-to-child transmission is another major way affecting intestinal flora. Studies have shown that children with obese mothers have increased inflammation and an increased risk of NAFLD ${ }^{(42)}$ (Fig. 5E). Conversely, probiotic therapy, that is, the ingestion of beneficial bacteria to build a normal and healthy intestinal microbial environment, can significantly reduce plasma ALT, TNF- $\alpha$ and IL-6 levels, increase the leptin content and insulin sensitivity, and reverse and inhibit the occurrence and development of liver inflammation $^{(43)}$. Supplementation with Lactobacillus rhamnosus has been reported to rebuild the balance of the intestinal flora and is effective against liver damage induced by alcohol in mice in a dose-dependent manner ${ }^{(44)}$. The intestinal flora can also affect the secretion of bile acids, thereby interfering with glucose and lipid metabolism in the liver ${ }^{(45)}$.

\section{Adipose tissue}

Throughout the body, metabolic changes naturally occur in various organs. The liver acts as the centre of metabolism in the body and is affected by multiple organs. Adipose tissue inflammation is verified to affect the occurrence and development of liver inflammation.

Population studies have shown that genes related to inflammation in subcutaneous fat tissue and visceral fat tissue are up-regulated, allowing macrophages in adipose tissue to secrete more pro-inflammatory factors. Moreover, the up-regulated genes are related to the severity of fatty liver ${ }^{(46)}$. The increased NEFAs and lipolysis activity in adipose tissue up-regulate macrophage activity, which is directly related to the degree of liver steatosis $^{(47)}$.

\section{Emerging pathways and factors}

In recent years, many emerging factors and possible pathways have been found to play roles in the occurrence of hepatitis. Here, we briefly summarise these factors, but further research is needed to better understand their effects on inflammation and lipid steatosis.

Unfolded protein response. The liver has a rich endoplasmic reticulum system that plays a role in keeping the steady state of liver cells, ensuring the metabolic processes proceed normally. The endoplasmic reticulum uses the unfolded protein response, an evolutionarily conserved approach, to maintain protein and lipid homeostasis in the liver. It has been reported that PERK-EIF2 $\alpha$ and IRE1 $\alpha$ in the unfolded protein response can induce inflammation, oxidative stress and death of liver cells $^{(48)}$.

Urea cycle. The urea cycle is a metabolic reaction that mainly occurs in the liver, functions as removing ammonia from the body. When exogenous ammonia enters and accumulates in the liver, it can cause liver dysfunction. Carbamoyl phosphate synthetase (CPS1) and ornithine carbamoyl transferase (OTC) are present in mitochondria and are key enzymes involved in the urea cycle. Mitochondrial damage decreases the expression of CPS1 and OTC, which leads to hyperammonaemia. In the diet- 
induced NASH model, expression of OTC was down-regulated both in mRNA and protein levels, causing further aggravation of liver disease ${ }^{(49)}$.

Advanced glycation end products. Advanced glycation end products (AGEs) are products of excess sugar and protein production. There are two sources of AGEs in the body. One source is excessive sugar and protein that react in the body to form AGEs spontaneously, the other source is intake of AGEs directly via food. AGEs are markers of hyperglycaemia and play pathogenic roles through the AGE receptor (RAGE). Studies have found that AGE/RAGE is closely related to the development of NAFLD. AGEs can increase liver TG levels, thereby promoting the development of simple fatty liver, and AGE/RAGE can induce the liver inflammatory response as well as promote the transition of NAFLD to NASH and liver fibrosis. Patients with hepatitis have high levels of RAGE, NF-кB/P65 and serum RAGE. In animal experiments, excessive intake of AGEs from a high-fat and high-sugar diet obviously caused liver lipid accumulation and fibrosis, pathological changes in hepatocyte balloon-like vacuoles, and increased content of 4-hydroxynonenal, a marker of chronic oxidative stress ${ }^{(50)}$.

microRNAs. microRNAs are a class of 20-24 nucleotide singlestranded non-protein-encoding small RNA molecules. miRNAs are abundant in the liver and participate in various processes of liver physiology and pathology (Fig. 5C), such as differentiation, growth and metabolism processes. miR144 has been shown to be highly expressed in obese individuals and obese mice livers, leading to an oxidative stress response by increasing NRF2 protein levels ${ }^{(51)}$. However, hepatitis caused by abnormal expression of miRNA is generally viral hepatitis, which leads to an increase in the replication of the virus at the genetic level ${ }^{(52,53)}$, while the effect on nutrition signalling by dietary intervention requires further investigation.

Emerging factors. A previous study found that cAMP-reactive element-binding protein was activated under endoplasmic reticulum stress or inflammatory stimulation, which induced acute liver inflammation ${ }^{(54)}$. Receptor-interacting protein kinase 1 inhibits mitochondrial respiratory chain activity, reduces $\beta$-oxidation, and improves NASH in mice fed a high-fat diet ${ }^{(55)}$. Bone morphogenetic protein 6 (BMP6), a transforming member of the growth factor $\beta$ (TGF- $\beta$ ) superfamily, has been shown to be up-regulated in NAFLD. Lipid accumulation in hepatocytes in vitro leads to the increased expression of BMP6. Knocking out BMP6 can inhibit the transition of NAFLD to hepatitis ${ }^{(56)}$. Type II interferon, also known as IFN- $\gamma$, is produced by mitogens to stimulate T-lymphocyte activity. Interferon is a biologically active substance with high antiviral function, and it is also a lymphokine with a wide range of immunomodulatory effects ${ }^{(57)}$. Studies have shown that IFN- $\boldsymbol{\gamma}$-knockout mice accelerate the development of NASH induced by TGF- $\beta$ and IL-13. Zinc- $\alpha 2$-glycoprotein 1 was originally found in various cancers and was shown to alleviate the progression of fatty liver disease by inhibiting TNF $\alpha$-mediated inflammation and intracellular lipid deposition $^{(58)}$.
mTORC1 may be the core regulator of carbohydratemediated inflammation and induce lipid deposition

Above, we discussed the correlation and possible mechanism of inflammation and carbohydrate intake. Lipid production and inflammation are not two separate events. Research has shown that increased inflammation aggravates the accumulation of lipids in the liver. In this section, we will speculate on the specific pathways that are involved in inflammation and lipid production by analysing the latest literature.

Studies have shown that nivolumab, an anticancer drug that functions by enhancing the immune response in the body, has a side effect of causing severe fatty liver, which reminds that inflammation may trigger lipid accumulation ${ }^{(59,60)}$. Furthermore, researchers have shown that, by knocking out adenosine $2 \mathrm{~A}$ receptor (A2AR), a protein with anti-inflammatory effects, in macrophages, and co-cultured A2AR-knockdown macrophages with hepatocytes, a large number of fat deposits will form in the hepatocytes. Furthermore, lack of A2AR can significantly increase the expression of the transcription factor SREBP1c in hepatocytes, which may influence the progression of lipogenesis ${ }^{(61)}$.

Increasing evidence has confirmed that inflammation can mediate lipid synthesis, while the specific regulatory pathways have not been fully investigated. From the current literature, although it may not the main aim of studies, we will focus on inflammation-related data to infer the possible pathways of inflammation on lipid synthesis.

At present, the mechanistic target of rapamycin complex 1 (mTORC1) signalling pathway is one of the most well-studied pathways and has been proven to mediate inflammation and hepatic lipid accumulation. In 2018, a study showed that down-regulation of the SIRT1-DEPTOR-mTORC1 signalling pathway was a crucial determinant of alcoholic fatty liver disease. Abnormal activation of mTORC1 may be due to defects in DEP domain-containing mTOR-interacting protein (DEPTOR) and SIRT1. When DEPTOR and SIRT1 are targeted to selectively inhibit the mTORC1-S6K1 signalling pathway, they can effectively alleviate and improve alcoholic fatty liver disease ${ }^{(62)}$. In addition, studies have shown that RAPTOR (a key component of mTORC1) regulates prostaglandins synthesised by cyclooxygenase-2 (COX-2), thereby promoting beige fat production, while RAPTOR-deficient mice are resistant to diet-induced obesity, indicating that the mTORC1 pathway functions in hepatic inflammation. Mechanistically, mTORC1 can phosphorylate CREBregulated transcription coactivator 2 , leading to the binding of CREB to the COX-2 promoter. Inhibition of COX-2 attenuates the inhibitory effect of thermogenic gene expression caused by mTORC1, further explaining the regulatory mechanism of the mTORC1 pathway in inflammation ${ }^{(63)}$ (Fig. 6).

In addition, a large number of studies have described many other factors and show that chronic inflammation is related to hepatic lipid levels. Suppressor of cytokine signalling 3 affects metabolism in the body by inhibiting signal transduction of insulin and leptin, leading to increased inflammation and affecting serum lipid levels ${ }^{(64)}$. Similarly, thioredoxin-interacting protein, a core molecule involved in oxidative stress and inflammation, has been shown to interact with PRMT1 to affect the expression 
of lipogenesis-related proteins. The anti-inflammatory factor IL-22 has been shown to relieve hepatic steatosis caused by a high-fat diet. Overexpression of IL-22R1 inhibits the activation of STAT3 by recombinant murine IL-22(65).

In summary, the classic inflammatory mTORCR1 pathway or various inflammation-related factors may lead to the regulation of inflammation levels that can interfere with lipid production, further indicating that inflammation mediates lipid synthesis.

\section{Summary and outlook}

Carbohydrates are positively correlated with inflammation, and inflammation can increase lipid deposition through multiple pathways, which may explain why patients with NAFLD have a worse condition after changing to a 'vegetarian' diet.

Currently, there are few studies on starchy carbohydrates, and inevitably, the existence of multiple variables makes it difficult to define the function of carbohydrates in lipid metabolism. To better demonstrate the effect of carbohydrates on inflammation and the effect of inflammation on lipid production, the following topics should be studied in future research:

1. The effects of different types of carbohydrates. Carbohydrates can be subdivided into free sugars and polysaccharides, and each type of carbohydrate should be studied separately.
2. The effects of carbohydrates on inflammation. In previous studies, inflammation was thought to be a phenomenon caused by lipid production. However, our review shows that inflammation can be directly triggered by carbohydrates.

3. To explore the effects and mechanisms of carbohydrates on inflammation and lipid metabolism, large-scale sequencing should be carried out on the basis of variable control. The influence of other organs on liver inflammation, especially adipose tissue, the pancreas and the intestines, should be considered. The possible mechanism of the liver-brain-gut axis should also be studied.

4. Food in the diet undergoes a complex process of digestion, and every nutrient in the diet has different metabolic pathways. Therefore, it is difficult to identify the specific factor that ultimately affects metabolic progression. At present, it is less likely that a single factor affects metabolic progression; rather, multiple factors or multiple nutrients work together. Therefore, special attention should be given to the setting of diet formulas in the design of experiments.

5. Although many key factors and proteins influence inflammation in the liver, inflammation is basically attributed to NF- $\kappa \mathrm{B}$, MAPK/PPAR $\alpha$, intracellular inflammation and mitochondrial dysfunction. Regarding the mechanism by which inflammation leads to lipogenesis, most studies point to the mTOR pathway; however, the evidence present is not strong and 
direct to clarrify the underlying functions and mechanisms. This will be an aspect that needs to be studied in the future, and the proposal of new regulatory pathways or new regulatory factors will be particularly important.

In summary, the effect of carbohydrates on inflammation and the relationship between inflammation and lipid production have been neglected in previous studies. Answering these questions clearly will be of great significance to further understand human metabolism and treat diseases. Based on previous studies, this review extracted data from previous literature to analyse the correlation between carbohydrate intake and inflammation, and discussed the perspective that the inflammatory response increases hepatic lipid accumulation. Therefore, the hypothesis that carbohydrates can further aggravate liver lipid accumulation by activating the inflammatory response was proposed. Our laboratory has already proven this hypothesis in animals.

\section{Limitations}

This review collected data from four databases: PubMed, Clinicalkey, Web of Science and Scopus. In an attempt to cover most of the literature published in recent years, the collected articles were organised and analysed in detail. However, of the nearly 7000 articles collected using keywords, only 45 articles met the requirements of this review, which greatly limited the analysability of this review and was also the main limitation of this article. In addition, diet is a complex system with a large number of variables. Due to the limited information in articles, total carbohydrates were barely enough to divide into free sugars and starchy carbohydrates for analysis. There were not enough data to perform a more statistical analysis of detailed carbohydrate components. However, despite the small sample size, an obvious correlation was identified, indicating that there is indeed a link between carbohydrates and inflammation. In addition, some researchers have carried out other forms of interventions without changing the intake of carbohydrates. These interventions also have effects on inflammation throughout the body. Therefore, it is necessary to exclude these data from analysis. Carbohydrates are not the only major influencing factor, which somewhat interferes with our analysis. It is hoped that a more detailed classification and grading of dietary intake will be performed in future population experiments to allow more powerful and detailed analyses.

\section{Acknowledgements}

This work was financially supported by grants from the National Natural Science Foundation of China (81871095), the National Key R\&D Program of China (2018YFC2000304), the Key International S\&T Cooperation Program of China (2016YFE113700) and the Advanced Innovation Center for Structure Biology of Tsinghua University (100300001).

There are no conflicts of interest.

The authors' responsibilities were as follows: Y.Q.G. and Z.W. developed the idea for this article; Y.Q.G., R.H. and K.Q.H. performed the literature search and data analysis; Y.Q.G., R.H.,
K.Q.H. and Z.W. wrote and critically revised the manuscript. All the authors have read and approved the final manuscript.

\section{References}

1. Kroemer G, Lopez-Otin C, Madeo F, et al. (2018) Carbotoxicity-Noxious effects of carbohydrates. Cell 175, 605-614.

2. Roager HM, Vogt JK, Kristensen M, et al. (2019) Whole grain-rich diet reduces body weight and systemic low-grade inflammation without inducing major changes of the gut microbiome: a randomised cross-over trial. Gut 68, 83-93.

3. Seidelmann SB, Claggett B, Cheng S, et al. (2018) Dietary carbohydrate intake and mortality: a prospective cohort study and meta-analysis. The Lancet Public Health 3, e419-e428.

4. Sanders FWB, Acharjee A, Walker C, et al. (2018) Hepatic steatosis risk is partly driven by increased de novo lipogenesis following carbohydrate consumption. Genome Biol 19, 79.

5. Hudgins LC, Parker TS, Levine DM, et al. (2011) A dual sugar challenge test for lipogenic sensitivity to dietary fructose. J Clin Endocrinol Metab 96, 861-868.

6. Antunes MM, Godoy G, de Almeida-Souza CB, et al. (2020) A high-carbohydrate diet induces greater inflammation than a high-fat diet in mouse skeletal muscle. Braz J Med Biol Res 53, e9039.

7. Myette-Côté É, Durrer C, Neudorf H, et al. (2018) The effect of a short-term low-carbohydrate, high-fat diet with or without postmeal walks on glycemic control and inflammation in type 2 diabetes: a randomized trial. Am J Physiol Regul Integr Comp Physiol 315, R1210-R1219.

8. Liu X, Burhans MS, Flowers MT, et al. (2016) Hepatic oleate regulates liver stress response partially through PGC-1alpha during high-carbohydrate feeding. I Hepatol 65, 103-112.

9. Tanaka N, Aoyama T, Kimura S, et al. (2017) Targeting nuclear receptors for the treatment of fatty liver disease. Pharmacol Ther 179, 142-157.

10. Franklin MP, Sathyanarayan A \& Mashek DG (2017) Acyl-CoA thioesterase 1 (ACOT1) regulates PPAR $\alpha$ to couple fatty acid flux with oxidative capacity during fasting. Diabetes $\mathbf{6 6}$, 2112-2123.

11. Peeters A \& Baes M (2010) Role of PPAR $\alpha$ in hepatic carbohydrate metabolism. PPAR Res 2010, 12.

12. Li Y, Chen M, Zhou Y, et al. (2020) NIK links inflammation to hepatic steatosis by suppressing PPAR $\alpha$ in alcoholic liver disease. Theranostics 10, 3579-3593.

13. Planavila A, Iglesias R, Giralt M, et al. (2011) Sirt1 acts in association with PPAR $\alpha$ to protect the heart from hypertrophy, metabolic dysregulation, and inflammation. Cardiovasc Res 90, 276-284.

14. Naiman S, Huynh FK, Gil R, et al. (2019) SIRT6 promotes hepatic beta-oxidation via activation of PPAR $\alpha$. Cell Rep 29, 4127-4143.e4128.

15. Rinaldi B, Donniacuo M, Esposito E, et al. (2011) PPAR $\alpha$ mediates the anti-inflammatory effect of simvastatin in an experimental model of zymosan-induced multiple organ failure. Br J Pharmacol 163, 609-623.

16. Kersten $S$ (2014) Integrated physiology and systems biology of PPAR $\alpha$. Mol Metab 3, 354-371.

17. Huang K, Du M, Tan X, et al. (2017) PARP1-mediated PPAR $\alpha$ poly(ADP-ribosyl)ation suppresses fatty acid oxidation in non-alcoholic fatty liver disease. J Hepatol 66, 962-977.

18. Wang S, Yang FJ, Shang LC, et al. (2019) Puerarin protects against high-fat high-sucrose diet-induced non-alcoholic fatty liver disease by modulating PARP-1/PI3K/AKT signaling 
pathway and facilitating mitochondrial homeostasis. Phytother Res 33, 2347-2359.

19. Hinz $M \&$ \& Scheidereit $C$ (2014) The IкB kinase complex in $\mathrm{NF}-\kappa \mathrm{B}$ regulation and beyond. EMBO Rep 15, 46-61.

20. Eshraghian A, Nikeghbalian S, Geramizadeh B, et al. (2019) Characterization of biopsy proven non-alcoholic fatty liver disease in healthy non-obese and lean population of living liver donors: the impact of uric acid. Clin Res Hepatol Gastroenterol 44, 572-578.

21. Jensen T, Abdelmalek MF, Sullivan S, et al. (2018) Fructose and sugar: a major mediator of non-alcoholic fatty liver disease. J Hepatol 68, 1063-1075.

22. de Zoete MR, Palm NW, Zhu S, et al. (2014) Inflammasomes. Cold Spring Harbor Perspect Biol 6, a016287.

23. Mridha AR, Wree A, Robertson AAB, et al. (2017) NLRP3 inflammasome blockade reduces liver inflammation and fibrosis in experimental NASH in mice. J Hepatol 66, 1037-1046.

24. Wan X, Xu C, Lin Y, et al. (2016) Uric acid regulates hepatic steatosis and insulin resistance through the NLRP3 inflammasome-dependent mechanism. J Hepatol 64, 925-932.

25. Juraschek SP, McAdams-Demarco M, Gelber AC, et al. (2016) Effects of lowering glycemic index of dietary carbohydrate on plasma uric acid levels: the OmniCarb randomized clinical trial. Arthritis Rheumatol 68, 1281-1289.

26. Zhang F, Jiang WW, Li X, et al. (2016) Role of intrahepatic B cells in non-alcoholic fatty liver disease by secreting pro-inflammatory cytokines and regulating intrahepatic $\mathrm{T}$ cells. J Dig Dis 17, 464-474.

27. Luo X, Li H, Ma L, et al. (2018) Expression of STING is increased in liver tissues from patients with NAFLD and promotes macrophage-mediated hepatic inflammation and fibrosis in mice. Gastroenterology 155, 1971-1984.e1974.

28. Huang Z, Wu LM, Zhang JL et al. (2019) Dual specificity phosphatase 12 regulates hepatic lipid metabolism through inhibition of the lipogenesis and apoptosis signal-regulating kinase 1 pathways. Hepatology 70, 1099-1118.

29. Zhao L, Zhang C, Luo X, et al. (2018) CD36 palmitoylation disrupts free fatty acid metabolism and promotes tissue inflammation in non-alcoholic steatohepatitis. J Hepatol 69, 705-717.

30. Lou Y, Han M, Liu H, et al. (2019) Essential roles of S100A10 in Toll-like receptor signaling and immunity to infection. Cell Mol Immunol.

31. Jia L, Chang X, Qian S, et al. (2018) Hepatocyte toll-like receptor 4 deficiency protects against alcohol-induced fatty liver disease. Mol Metab 14, 121-129.

32. Zhao GN, Zhang P, Gong J, et al. (2017) Tmbim1 is a multivesicular body regulator that protects against non-alcoholic fatty liver disease in mice and monkeys by targeting the lysosomal degradation of Tlr4. Nat Med 23, 742-752.

33. Mazat JP, Devin A \& Ransac S (2020) Modelling mitochondrial ROS production by the respiratory chain. Cell Mol Life Sci 77, 455-465.

34. Nisr RB, Shah DS, Ganley IG, et al. (2019) Proinflammatory NFkB signalling promotes mitochondrial dysfunction in skeletal muscle in response to cellular fuel overloading. Cell Mol Life Sci 76, 4887-4904.

35. Das A, Weigle AT, Arnold WR, et al. (2020) CYP2J2 molecular recognition: a new axis for therapeutic design. Pharmacol Ther 215, 107601.

36. Jian T, Ao X, Wu Y, et al. (2017) Total sesquiterpene glycosides from Loquat (Eriobotrya japonica) leaf alleviate high-fat diet induced non-alcoholic fatty liver disease through cytochrome P450 2E1 inhibition. Biomed Pharmacother 91, 229-237.
37. Leung TM \& Nieto N (2013) CYP2E1 and oxidant stress in alcoholic and non-alcoholic fatty liver disease. $J$ Hepatol $\mathbf{5 8}$, 395-398.

38. Simpson SJ, Raubenheimer D, Cogger VC, et al. (2018) The nutritional geometry of liver disease including non-alcoholic fatty liver disease. J Hepatol 68, 316-325.

39. Nagpal R, Shively CA, Appt SA, et al. (2018) Gut microbiome composition in non-human primates consuming a Western or Mediterranean diet. Front Nutr 5, 28.

40. Ley RE, Turnbaugh PJ, Klein S \& Gordon JI (2006) Microbial ecology human gut microbes associated with obesity. Nature 444, 1022-1023.

41. Bäckhed F, Ding H, Wang T, et al. (2004) The gut microbiota as an environmental factor that regulates fat storage. PNAS 101, 15718-15723.

42. Soderborg TK, Clark SE, Mulligan CE, et al. (2018) The gut microbiota in infants of obese mothers increases inflammation and susceptibility to NAFLD. Nat Commun 9, 4462.

43. Al-Muzafar HM \& Amin KA (2017) Probiotic mixture improves fatty liver disease by virtue of its action on lipid profiles, leptin, and inflammatory biomarkers. BMC Complement Altern Med 17, 43 .

44. Gu Z, Wu Y, Wang Y, et al. (2020) Lactobacillus rhamnosus granules dose-dependently balance intestinal microbiome disorders and ameliorate chronic alcohol-induced liver injury. J Med Food 23, 114-124.

45. Jiao N, Baker SS, Chapa-Rodriguez A, et al. (2018) Suppressed hepatic bile acid signalling despite elevated production of primary and secondary bile acids in NAFLD. Gut 67, 1881-1891.

46. du Plessis J, van Pelt J, Korf H, et al. (2015) Association of adipose tissue inflammation with histologic severity of nonalcoholic fatty liver disease. Gastroenterology 149, 635-648 e614.

47. Rosso C, Kazankov K, Younes R, et al. (2019) Crosstalk between adipose tissue insulin resistance and liver macrophages in non-alcoholic fatty liver disease. J Hepatol $\mathbf{7 1}$, 1012-1021.

48. Lebeaupin C, Vallee D, Hazari Y, et al. (2018) Endoplasmic reticulum stress signalling and the pathogenesis of nonalcoholic fatty liver disease. J Hepatol 69, 927-947.

49. De Chiara F, Heeboll S, Marrone G, et al. (2018) Urea cycle dysregulation in non-alcoholic fatty liver disease. $J$ Hepatol 69, 905-915.

50. Leung C, Herath CB, Jia Z, et al. (2016) Dietary advanced glycation end-products aggravate non-alcoholic fatty liver disease. World J Gastroenterol 22, 8026-8040.

51. Eigentler T, Lomberg D, Machann J, et al. (2020) Lipodystrophic nonalcoholic fatty liver disease induced by immune checkpoint blockade. Ann Intern Med 172, 836-837.

52. Su Q, Kumar V, Sud N, et al. (2018) MicroRNAs in the pathogenesis and treatment of progressive liver injury in NAFLD and liver fibrosis. Adv Drug Deliv Rev 129, 54-63.

53. He Z, Yang JJ, Zhang R, et al. (2019) Circulating miR-29b positively correlates with non-alcoholic fatty liver disease in a Chinese population. J Dig Dis 20, 189-195.

54. Zhang C, Wang G, Zheng Z, et al. (2012) Endoplasmic reticulum-tethered transcription factor cAMP responsive element-binding protein, hepatocyte specific, regulates hepatic lipogenesis, fatty acid oxidation, and lipolysis upon metabolic stress in mice. Hepatology 55, 1070-1082.

55. Majdi A, Aoudjehane L, Ratziu V, et al. (2020) Inhibition of receptor-interacting protein kinase 1 improves experimental non-alcoholic fatty liver disease. J Hepatol 72, 627-635. 
56. Arndt S, Wacker E, Dorn C, et al. (2015) Enhanced expression of BMP6 inhibits hepatic fibrosis in non-alcoholic fatty liver disease. Gut 64, 973-981.

57. Kak G, Raza M \& Tiwari BK (2018) Interferon-gamma (IFN- $\gamma$ ): exploring its implications in infectious diseases. Biomol Concepts 9, 64-79.

58. Liu T, Luo X, Li ZH, et al. (2019) Zinc-alpha2-glycoprotein 1 attenuates non-alcoholic fatty liver disease by negatively regulating tumour necrosis factor-alpha. World J Gastroenterol 25, 5451-5468.

59. Sawada K, Hayashi H, Nakajima S, et al. (2020) Non-alcoholic fatty liver disease is a potential risk factor for liver injury caused by immune checkpoint inhibitor. J Gastroenterol Hepatol 35, 1042-1048.

60. Tighe SP, Iqbal U, Fernandes CT, et al. (2019) Treatment of inoperable hepatocellular carcinoma with immunotherapy. BMJ Case Rep 12, e229744.

61. Cai Y, Li H, Liu M, et al. (2018) Disruption of adenosine 2A receptor exacerbates NAFLD through increasing inflammatory responses and SREBP1c activity. Hepatology 68, 48-61.

62. Peterson TR, Laplante M, Thoreen CC, et al. (2009) DEPTOR is an mTOR inhibitor frequently overexpressed in multiple myeloma cells and required for their survival. Cell 137, 873-886

63. Zhang X, Luo Y, Wang C, et al. (2018) Adipose mTORC1 suppresses prostaglandin signaling and beige adipogenesis via the CRTC2-COX-2 pathway. Cell Rep 24, 3180-3193.

64. Levinthal DJ \& Strick PL (2020) Multiple areas of the cerebral cortex influence the stomach. Proc Natl Acad Sci 117, 1307813083.

65. Yang L, Zhang Y, Wang L, et al. (2010) Amelioration of high fat diet induced liver lipogenesis and hepatic steatosis by interleukin-22. J Hepatol 53, 339-347.

66. Alferink LJ, Kiefte-de Jong JC, Erler NS, et al. (2019) Association of dietary macronutrient composition and non-alcoholic fatty liver disease in an ageing population: the Rotterdam Study. Gut 68, 1088-1098.

67. Wu HT, Lu FH, Ou HY, et al. (2013) The role of hepassocin in the development of non-alcoholic fatty liver disease.J Hepatol 59, 1065-1072.

68. Ryan MC, Itsiopoulos C, Thodis T, et al. (2013) The Mediterranean diet improves hepatic steatosis and insulin sensitivity in individuals with non-alcoholic fatty liver disease. J Hepatol 59, 138-143.

69. Li C, Guo P, Okekunle AP, et al. (2019) Lean non-alcoholic fatty liver disease patients had comparable total caloric, carbohydrate, protein, fat, iron, sleep duration and overtime work as obese non-alcoholic fatty liver disease patients. J Gastroenterol Hepatol 34, 256-262.

70. Tayyem RF, Al-Dayyat HM \& Rayyan YM (2019) Relationship between lifestyle factors and nutritional status and nonalcoholic fatty liver disease among a group of adult Jordanians. Arab J Gastroenterol 20, 44-49.

71. Jang EC, Jun DW, Lee SM, et al. (2018) Comparison of efficacy of low-carbohydrate and low-fat diet education programs in non-alcoholic fatty liver disease: a randomized controlled study. Hepatol Res 48, E22-E29.

72. Razavi Zade M, Telkabadi MH, Bahmani F, et al. (2016) The effects of DASH diet on weight loss and metabolic status in adults with non-alcoholic fatty liver disease: a randomized clinical trial. Liver Int 36, 563-571.

73. Maleki Z, Jazayeri S, Eslami O, et al. (2019) Effect of soy milk consumption on glycemic status, blood pressure, fibrinogen and malondialdehyde in patients with non-alcoholic fatty liver disease: a randomized controlled trial. Complement Ther Med 44, 44-50.
74. Goss AM, Dowla S, Pendergrass M, et al. (2020) Effects of a carbohydrate-restricted diet on hepatic lipid content in adolescents with non-alcoholic fatty liver disease: a pilot, randomized trial. Pediatr Obes $\mathbf{1 5}$, e12630.

75. Aller R, Izaola O, Gomez S, et al. (2015) Effect of silymarin plus vitamin $\mathrm{E}$ in patients with non-alcoholic fatty liver disease. A randomized clinical pilot study. Eur Rev Med Pharmacol Sci 19, 3118-3124.

76. Ma J, Fox CS, Jacques PF et al. (2015) Sugar-sweetened beverage, diet soda, and fatty liver disease in the Framingham Heart Study cohorts. J Hepatol 63, 462-469.

77. Silver HJ, Kang H, Keil CD, et al. (2014) Consuming a balanced high fat diet for 16 weeks improves body composition, inflammation and vascular function parameters in obese premenopausal women. Metabolism 63, 562-573.

78. de Luis D, Domingo JC, Izaola O, et al. (2016) Effect of DHA supplementation in a very low-calorie ketogenic diet in the treatment of obesity: a randomized clinical trial. Endocrine 54, 111-122.

79. Rajaie S, Azadbakht L, Khazaei M, et al. (2014) Moderate replacement of carbohydrates by dietary fats affects features of metabolic syndrome: a randomized crossover clinical trial. Nutrition 30, 61-68.

80. Tutunchi H, Ostadrahimi A, Saghafi-Asl M, et al. (2020) Oleoylethanolamide supplementation in obese patients newly diagnosed with non-alcoholic fatty liver disease: effects on metabolic parameters, anthropometric indices, and expression of PPAR-alpha, UCP1, and UCP2 genes. Pharmacol Res 156, 104770

81. Marin-Alejandre BA, Abete I, Monreal JI, et al. (2020) Effects of a 6-month dietary-induced weight loss on erythrocyte membrane omega-3 fatty acids and hepatic status of subjects with nonalcoholic fatty liver disease: the Fatty Liver in Obesity study. J Clin Lipidol 14, 837-849 e832.

82. Markova M, Pivovarova O, Hornemann S, et al. (2017) Isocaloric diets high in animal or plant protein reduce liver fat and inflammation in individuals with type 2 diabetes. Gastroenterology 152, 571-585 e 578.

83. Arendt BM, Teterina A, Pettinelli P et al. (2019) Cancer-related gene expression is associated with disease severity and modifiable lifestyle factors in non-alcoholic fatty liver disease. Nutrition 62, 100-107.

84. Mosca A, Nobili V, De Vito R, et al. (2017) Serum uric acid concentrations and fructose consumption are independently associated with NASH in children and adolescents. J Hepatol 66, 1031-1036

85. Gepner Y, Shelef I, Komy O, et al. (2019) The beneficial effects of Mediterranean diet over low-fat diet may be mediated by decreasing hepatic fat content. J Hepatol 71, 379-388.

86. Bhatt SP, Misra A, Nigam P (2019) Nutrition and physical activity in Asian Indians with non-alcoholic fatty liver: a case control study. Diabetes Metab Syndr 13, 1271-1274.

87. Lorvand Amiri H, Agah S, Tolouei Azar J et al. (2017) Effect of daily calcitriol supplementation with and without calcium on disease regression in non-alcoholic fatty liver patients following an energy-restricted diet: randomized, controlled, double-blind trial. Clin Nutr 36, 1490-1497.

88. Kwak JH, Jun DW, Lee SM, et al. (2018) Lifestyle predictors of obese and non-obese patients with nonalcoholic fatty liver disease: a cross-sectional study. Clin Nutr 37, 1550-1557.

89. Mikami K, Endo T, Sawada N, et al. (2020) Leptin/adiponectin ratio correlates with hepatic steatosis but not arterial stiffness in nonalcoholic fatty liver disease in Japanese population. Cytokine 126, 154927.

90. Parry SA, Rosqvist F, Mozes FE, et al. (2020) Intrahepatic fat and postprandial glycemia increase after consumption of a 
diet enriched in saturated fat compared with free sugars. Diabetes Care 43, 1134-1141.

91. Luukkonen PK, Dufour S, Lyu K, et al. (2020) Effect of a ketogenic diet on hepatic steatosis and hepatic mitochondrial metabolism in nonalcoholic fatty liver disease. PNAS 117, 7347-7354.

92. Aktary ML, Eller LK, Nicolucci AC, et al. (2020) Cross-sectional analysis of the health profile and dietary intake of a sample of Canadian adults diagnosed with non-alcoholic fatty liver disease. Food Nutr Res 64, 4548-4562.

93. Rosqvist F, Orho-Melander M, Kullberg J, et al. (2020) Abdominal fat and metabolic health markers but not PNPLA3 genotype predicts liver fat accumulation in response to excess intake of energy and saturated fat in healthy individuals. Front Nutr 7, 606004 .

94. Emamat H, Ghalandari H, Totmaj AS, et al. (2021) Calcium to magnesium intake ratio and non-alcoholic fatty liver disease development: a case-control study. BMC Endocr Disord 21, 51.

95. Della Pepa G, Vetrani C, Brancato V, et al. (2020) Effects of a multifactorial ecosustainable isocaloric diet on liver fat in patients with type 2 diabetes: randomized clinical trial. $B M J$ Open Diabetes Res Care 8, 4548-4562.

96. Rietman A, Sluik D, Feskens EJM, et al. (2018) Associations between dietary factors and markers of NAFLD in a general Dutch adult population. Eur J Clin Nutr 72, 117-123.

97. Cunha GM, Guzman G, Correa De Mello LL, et al. (2020) Efficacy of a 2-month very low-calorie Ketogenic diet (VLCKD) compared to a standard low-calorie diet in reducing visceral and liver fat accumulation in patients with obesity. Front Endocrinol (Lausanne) 11, 607.

98. Nikroo H, Nematy M, Attarzadeh Hosseini SR, et al. (2017) How does addition of regular aerobic exercises, influence the efficacy of calorie-restricted diet in patients with non-alcoholic steatohepatatis (NASH)? Hepat Mon 17, 1-8.

99. Goss AM, Dowla S, Pendergrass M, et al. (2020) Effects of a carbohydrate-restricted diet on hepatic lipid content in adolescents with non-alcoholic fatty liver disease: a pilot, randomized trial. Pediatr Obes 15, e12630.

100. Properzi C, O'Sullivan TA, Sherriff JL, et al. (2018) Ad libitum Mediterranean and low-fat diets both significantly reduce hepatic steatosis: a randomized controlled trial. Hepatology (Baltimore, Md) 68, 1741-1754

101. Kaliora AC, Kalafati IP, Gioxari A, et al. (2018) A modified response of NAFLD patients with non-significant fibrosis in nutritional counseling according to GCKR rs1260326. Eur J Nutr 57, 2227-2235.

102. Marin-Alejandre BA, Abete I, Cantero I et al. (2019) The metabolic and hepatic impact of two personalized dietary strategies in subjects with obesity and nonalcoholic fatty liver disease: the Fatty Liver in Obesity (FLiO) randomized controlled trial. Nutrients 11, 2543.

103. Watanabe M, Risi R, Camajani E, et al. (2020) Baseline HOMA IR and circulating FGF21 levels predict NAFLD improvement in patients undergoing a low carbohydrate dietary intervention for weight loss: a prospective observational pilot study. Nutrients 12, 2141.

104. Lahelma M, Luukkonen PK, Qadri S, et al. (2021) Assessment of lifestyle factors helps to identify liver fibrosis due to non-alcoholic fatty liver disease in obesity. Nutrients 13, 169

105. Crabtree CD, Kackley ML, Buga A, et al. (2021) Comparison of ketogenic diets with and without ketone salts versus a low-fat diet: liver fat responses in overweight adults. Nutrients $\mathbf{1 3}$, 966.

106. Cheng S, Ge J, Zhao C, et al. (2017) Effect of aerobic exercise and diet on liver fat in pre-diabetic patients with nonalcoholic-fatty-liver-disease: a randomized controlled trial. Sci Rep 7, 15952

107. Szabo G \& Petrasek J (2015) Inflammasome activation and function in liver disease. Nat Rev Gastroenterol Hepatol 12, 387-400. 